\title{
High-resolution Hindcasts for U.S. Wave Energy Resource Characterization
}

\author{
Zhaoqing Yang and Vincent S. Neary
}

\begin{abstract}
The marine and hydrokinetic (MHK) industry is at an early stage of development and has the potential to play a significant role in diversifying the U.S. energy portfolio and reducing the U.S. carbon footprint. Wave energy is the largest among all the U.S. MHK energy resources, which include wave energy, ocean current, tidalinstream, ocean thermal energy conversion, and riverinstream. Wave resource characterization is an essential step for regional wave energy assessments, Wave Energy Converter (WEC) project development, site selection and WEC design. The present paper provides an overview of a joint modelling effort by the Pacific Northwest National Laboratory and Sandia National Laboratories on highresolution wave hindcasts to support the U.S. Department of Energy's Water Power Technologies Office's program of wave resource characterization, assessment and classifications in all US coastal regions. Topics covered include the modelling approach, model input requirements, model validation strategies, high performance computing resource requirements, model outputs and data management strategies. Examples of model setup and validation for different regions are provided along with application to development of classification systems, and analysis of regional wave climates. Lessons learned and technical challenges of the long-term, high-resolution regional wave hindcast are discussed.
\end{abstract}

Keywords-U.S. regional wave hindcast, unstructuredgrid wave model, model validation, resource characterization, classification systems.

\section{INTRODUCTION}

$\mathrm{T}$ HE WEC industry lacks sufficient knowledge of resource characteristics important to device design and project development due to the absence of accurate high-resolution spatial and temporal wave spectral data. The knowledge gaps include lack of International Electrotechnical Commission (IEC) parameters associated with wave resource attributes [1], statistics to characterize risks associated with extreme wave events, and classification schemes that codify these characteristics for energy planners, project developers, and

Manuscript received 16 March; accepted 26 March; published 8 Sept, 2020. This is an open access article distributed under the terms of the Creative Commons Attribution 4.0 licence (CC BY https:// creativecommons.org/licenses/by/4.0/). This study was funded by the U.S. Department of Energy, Office of Energy Efficiency and Renewable Energy, Water Power Technology Office, under contract DE-AC05-76RL01830.
WEC designers. This knowledge is particularly lacking in shallow nearshore regions. These important wave energy resource parameters are the building blocks for upgrading the U.S. Department of Energy's (DOE) web-based GIS tool, the marine-hydrokinetic (MHK) ATLAS, designed to archive and disseminate information on resource characteristics; and for developing the U.S. DOE's resource classification systems for streamlining resource assessment and Wave Energy Converter (WEC) design. As part of a multi-national labs effort, with funding support from DOE's Office of Energy Efficiency and Renewable Energy (EERE), Water Power Technologies Office (WPTO), this modelling project details highresolution wave hindcasts for wave resource characteristics at regional scales and provides the data needed for technical and business decisions that are critical to early-stage MHK technology development and commercialization.

The absence of a wave resource classification scheme currently represents a significant market barrier to WEC technology development and commercialization. Key wave energy resource statistics recommended by the IEC Technical Specification, IEC 62600-101 TS [1] needs to be codified to delineate opportunities for wave power extraction, and risks to operation and maintenance (O\&M), operational reliability, and survival, similar to what has been done in the wind industry. Data on resource characteristics, derived from high-resolution wave models can be used to develop a wave classification scheme for U.S. coastal waters, which accelerates wave technology development by providing device developers with a framework for designing WEC technologies.

The wave energy resource assessment conducted by the Electrical Power Research Institute (EPRI) [2] provided valuable first order estimates of the U.S. wave energy resource at a national scale. As a reconnaissance (Class 1) characterization with high uncertainty [1], it did not attempt to provide outputs that could be used for development of a wave resource classification scheme, and essential parameters for project siting, feasibility studies, device design, and array deployments. The EPRI study

This article has been subject to single-blind peer review by a minimum of two reviewers. Z. Yang is with the Marine Sciences Laboratory in the Pacific Northwest National Laboratory, 1100 Dexter Ave North, Suite 500, Seattle, WA, USA. (e-mail: zhaoqing.yang@pnnl.gov). V. S. Neary is with the water power technologies program with Sandia National Laboratories, P.O. Box 5800, Albuquerque, NM 87185-MS1124, USA. (e-mail: vsneary@sandia.gov)

Digital Object Identifier https://doi.org/10.36688/imej.3.65-71 
used the National Oceanic and Atmospheric Administration's (NOAA's) global-regional nested WaveWatchIII (WWIII) hindcast. Therefore, the finest grid resolution was 4 -arc-minute $(\sim 5 \mathrm{~km}-7 \mathrm{~km})$, which barely met the IEC TS standard of minimum $5 \mathrm{~km}$ grid resolution for class 1 (reconnaissance) assessment and was too coarse to accurately characterize wave resources in nearshore shallow-water areas. In addition, the period of simulation was less than 5 years ( 51 months), well below the IEC recommended twenty years to accurately derive extreme wave statistics [1]. Therefore, more accurate regional wave hindcasts should be followed at finer resolutions, such as a minimum spatial resolution of $500 \mathrm{~m}$ for class 2 (feasibility) resource assessments.

This paper presents an on-going regional wave hindcast effort, jointly carried out by DOE's Pacific Northwest National Laboratory and the Sandia National Laboratories. This project will provide industry with resource specifications that are important to designing economical WEC and optimal siting. Specifically, the project team is undertaking the effort of conducting longterm, high-resolution wave hindcasts in all U.S. Exclusive Economic Zone (EEZ) (Fig. 1), using state-of-the-art wave models, physics packages and modelling approaches. The U.S. EEZ is the second largest after France, with a total area of $11,351,000 \mathrm{~km}^{2}$. The areas of each sub-region in US EEZ are listed in Table 1.

The feasibility characterization, with a spatial resolution less than $500 \mathrm{~m}$, allow assessment with relatively less uncertainty required for project feasibility and design studies. These regional hindcast models in present study are designed to meets the requirements for a feasibility (Class 2) characterization at a resolution of $\sim 200$ to $300 \mathrm{~m}$ within the coastal region's economic exclusion zone [1].

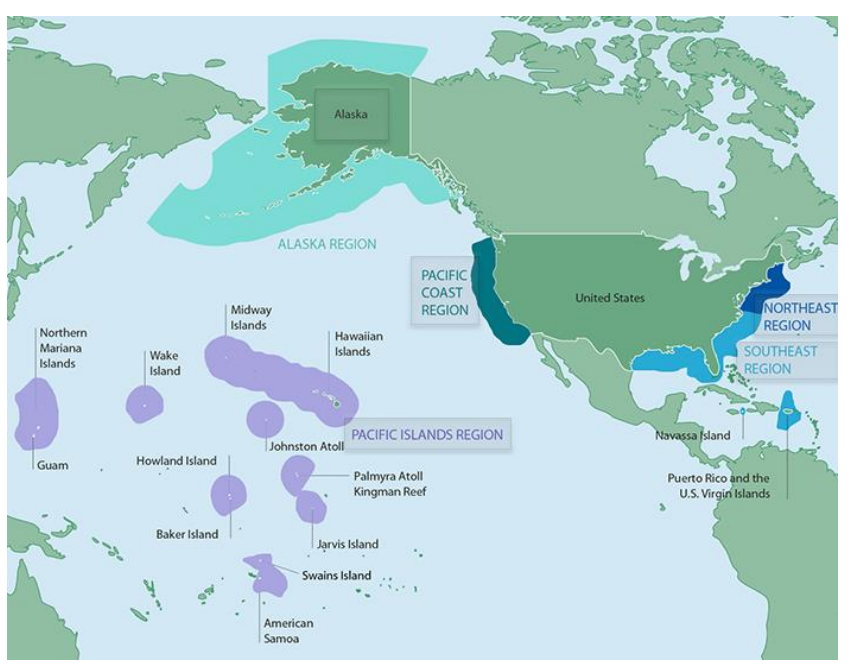

Fig. 1. U.S. EEZ consists of following sub-regions: (a) West Coast; (b) East Coast (Northeast and Southeast regions); (c) Alaska; (d) Gulf of Mexico; (e) Puerto Rico and U.S. Virgin Islands; (f) Hawaii and Pacific Islands. EEZ is defined as a sea zone that extends $370 \mathrm{~km}$ (200 nmi) offshore from its coastal baseline. The image is obtained from NOAA National Ocean Service.
TABLE I

AREA AND MODEL HINDCAST STATUS FOR U.S. EEZ REGIONS

\begin{tabular}{lcc}
\hline Region & Area $\left(\mathrm{km}^{2}\right)$ & Hindcast Status \\
\hline West Coast & 825,549 & Complete \\
East Coast & 915,763 & Complete \\
Alaska & $3,770,021$ & Complete \\
Gulf of Mexico & 707,832 & 2019 \\
Hawaii Islands & $1,579,538$ & 2019 \\
Pacific Islands & $3,328,925$ & 2020 \\
Puerto Rico and & 211,429 & 2020 \\
U.S. Virgin Islands & & \\
\hline
\end{tabular}

\section{MODELLING APPROACH}

\section{A. Wave models}

Two of the most well-known third-generation, phaseaveraged models, WaveWatchIII ${ }^{\circledR}$ (WWIII) [3] and Simulating WA Nearshore (SWAN) [4], were used in this study. Both models solve the same wave action balance equation but with different numerical schemes:

$$
\frac{D N}{D t}=\frac{1}{\sigma}\left(S_{i n}+S_{d s}+S_{n l}+S_{b o t}+S_{b r k}\right)
$$

where $N$ the wave action, $t$ is time, $\sigma$ is the radian frequency. $S_{\text {in }}$ is wind energy input and dissipation due to whitecapping $\left(S_{d s}\right)$ [5]. $S_{n l}$ is the non-linear quadruplet interactions; $S_{b o t}$ and $S_{b o t}$ represent energy dissipation due to bottom friction and depth-induced wave breaking, respectively. For details on the model frameworks of WWIII and SWAN, readers are referred to [3, 4].

In this study, global-regional three-level nested WWIII modelling framework developed by NOAA was adopted and simulations were conducted to generate spectral outputs at hourly intervals to drive the high-resolution regional UnSWAN hindcasts. The WWIII model configurations were kept the same as the NOAA's model configurations. The ST4 physics package for the source terms in WWIII was used. In this study, the unstructuredgrid version of SWAN (UnSWAN) [6] was used to conduct high-resolution regional wave hindcasts for all the US coastal regions. The unstructured-grid modelling framework will improve the computational efficiently and simulation accuracy with high-resolution representation of complex coastal systems [7-9].

\section{B. Model configurations}

All model configurations generally adopt similar model physics, frequency and direction resolutions, following a test bed study [10].

Development of high-resolution unstructured grids for these large regional model domain could be challenging. Approaches for model grid development varied slightly among the regions, depending on different wave climates and bottom topographic features of the nearshore region and inner continental shelves. For example, the West Coast 
has very narrow continental shelf therefore shallow-water effect does not occur until waves propagate close to shore. Fig. 2a shows the model bathymetry in the UnSWAN domain in the west coast and Fig. 2b-c shows the detailed grid distribution near the mouth of Columbia River and San Francisco Bay. The UnSWAN model domain covers the inner shelf area extended to approximately $30 \mathrm{~km}$ offshore, where water depth is mostly deeper than $500 \mathrm{~m}$. The grid resolution varies from approximately $200 \mathrm{~m}$ along the shoreline to $350 \mathrm{~m}$ at the open boundary. The West Coast model domain consists of approximately 435,000 gridpoints.
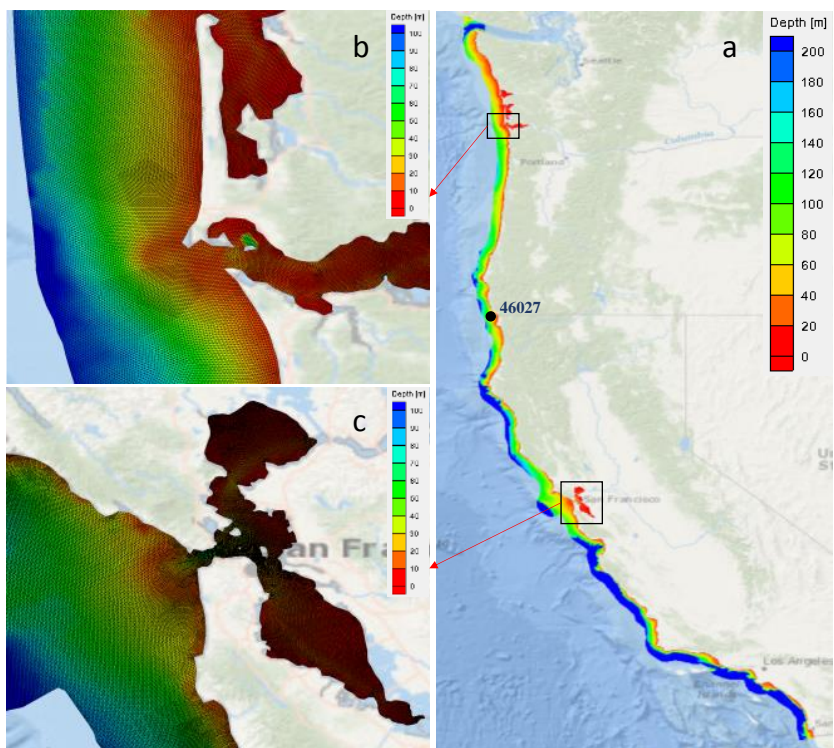

Fig. 2. UnSAWN model domain for U.S. West Coast (a), zoomed-in model grids near the mouth of Columbia River (b) and San Francisco Bay (c).

In contrast, the East Coast has much wider and shallower continental shelf. The East Coast regional model employs a single ultra-high-resolution unstructured mesh composed of over 4-million gridpoints and encompassing the entire coastal and inner shelf regions along the entire US eastern coastline and offshore regions of the western Atlantic Basin. Modelled JONSWAP spectra using bulk wave parameters from NOAA's global WWIII model, including height, peak period and direction, are prescribed along the model open boundary offshore at 61.0-degrees W longitude (Fig. 3) such that the model can properly simulate the large waves induced by tropical storms propagating from the tropical and subtropical Atlantic Ocean. Model grid size is about $200 \mathrm{~m}$ within $20 \mathrm{~km}$ offshore and gradually increase to $2,600 \mathrm{~m}$ along the open boundary. Details of the East Coast regional model, including its development and validation are found in [8].
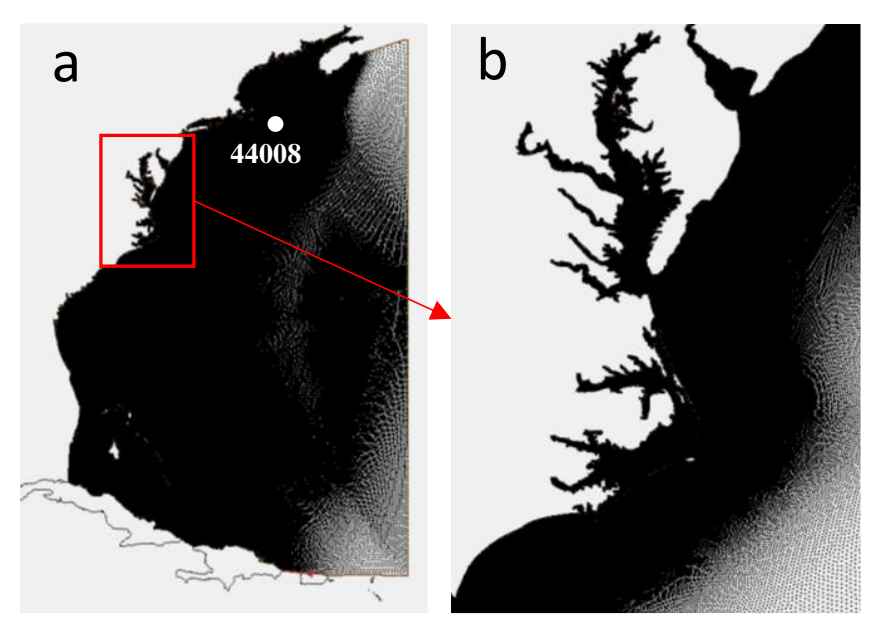

Fig. 3. UnSAWN model grid for U.S. East Coast (a) and zoomed-in near the Chesapeake Bay region (b).

The U.S. Alaska region consists of the largest EEZ (Table 1). The model domain for the Alaska region is also the most complicated among all the U.S. EEZ because of the presence of Aleutian Islands and complex shorelines. The UnSWAN model domain covers the entire EEZ boundary, approximately $370 \mathrm{~km}$ offshore (Fig. 4). The model grid resolution in the nearshore areas is specified as $300 \mathrm{~m}$ and gradually transition to $4 \mathrm{~km}$ at the open boundary along the EEZ boundary. There are nearly 4-million gridpoints in the Alaska UnSWAN model grid.

Model bathymetries for all three model domains were interpolated from NOAA's 1-arc-minute ETOPO1 Global Relief Model for the outer-shelf region and the 3-arcsecond Coastal Relief Model for the inner-shelf region.

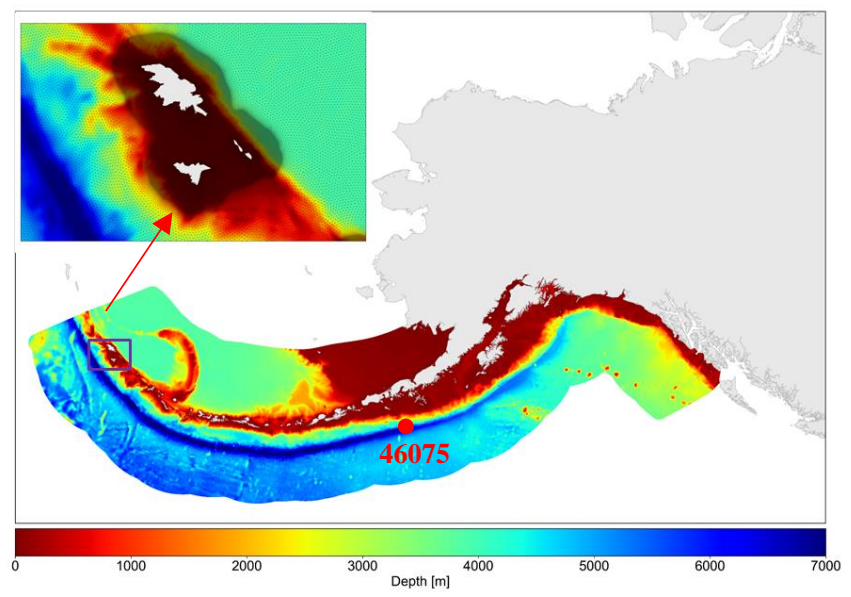

Fig. 4. UnSAWN model domain and grid for U.S. Alaska Coast.

To meet the IEC requirements for wave hindcasts in feasibility resource assessments, both WWIII and UnSWAN use 29 spectral frequency bins ranging from 0.035 to $0.505 \mathrm{~Hz}$ with a logarithmic increment factor of 1.1 in all three regions (West Coast, East Coast and Alaska). Twenty-four directional bins with a resolution of 15 degrees were specified for West Coast and East. However, initial model tests for Alaska region showed the Garden Sprinkler Effect (GSE) along the Aleutian Islands of Alaska. To alleviate this effect, the directional resolution 
was increased from 15 degrees to 5 degrees with 72 bins for the Alaska model configuration. A time step of 1minute was used for all the UnSWAN simulations. This time step is sufficient to resolve the time variations of the computed wave field, given that the wind forcing and open boundary conditions are at hourly intervals. More detailed model configurations can be found in [7-9].

Accurate wind forcing is extremely important for the wave hindcast. Wang et al. [11] evaluated several wind products, and concluded that the Climate Forecast System Reanalysis (CFSR) provided the best overall performance in predicting wave heights using either WWIII or UnSWAN. The CFSR wind data are available from 1979 to 2010 at hourly temporal and 0.5-degree spatial resolution.

A snapshot of the global CFSR wind speed distribution and the corresponding significant wave height simulated by WWIII during the September 2005 Hurricane Katrina event is provided in Fig. 5. We can see that the intensification of Hurricane Katrina and the resultant extreme wave were well-captured in the CFSR wind field and WWIII simulated wave field. It also can be seen that a number of extra-tropical cyclones are represented in CFSR and significant wave height in the Pacific Ocean.

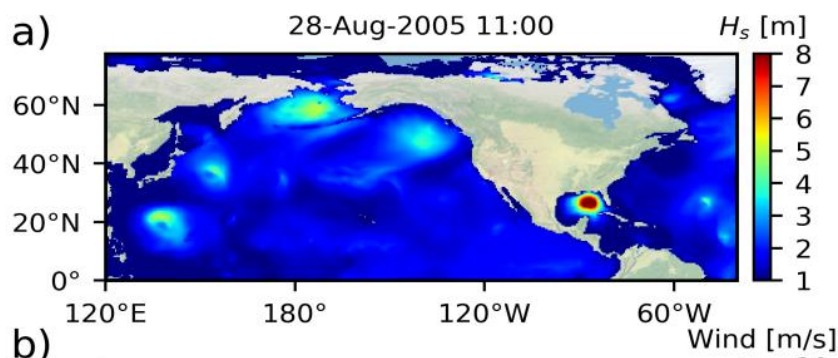

b)

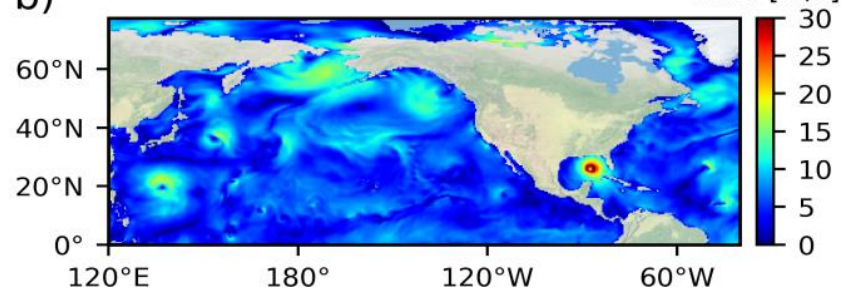

Fig. 5. Snapshots of simulated global significant wave height with WWIII (a) and CFSR surface wind (b) during Hurricane Katrina on August 28, 2005

\section{REGIONAL MODEL HINDCAST}

\section{Model validation}

We conducted 32 years (1979 - 2010) of long-term model simulations for all three regions. Model simulations for the West Coast and Alaska Coast were performed at the PPNL Institutional Computing (PIC) facility and simulations for the East Coast were performed at the Sky Bridge high performance computing cluster hosted at Sandia National Laboratories.

While the purpose of this paper is not to provide indepth discussion of the 32-years high-resolution hindcast results, an example of simulated two-dimensional (2D) distribution of significant wave height from UnSWAN in
Kodiak of Alaska, in comparison to the result from NOAA's 4-arc-minute WWIII, is shown in Fig. 6. Clearly, the UnSWAN results (Fig. 6a) provide much more detailed and accurate information of the wave climate around Kodiak than the WWIII results (Fig. 6b).

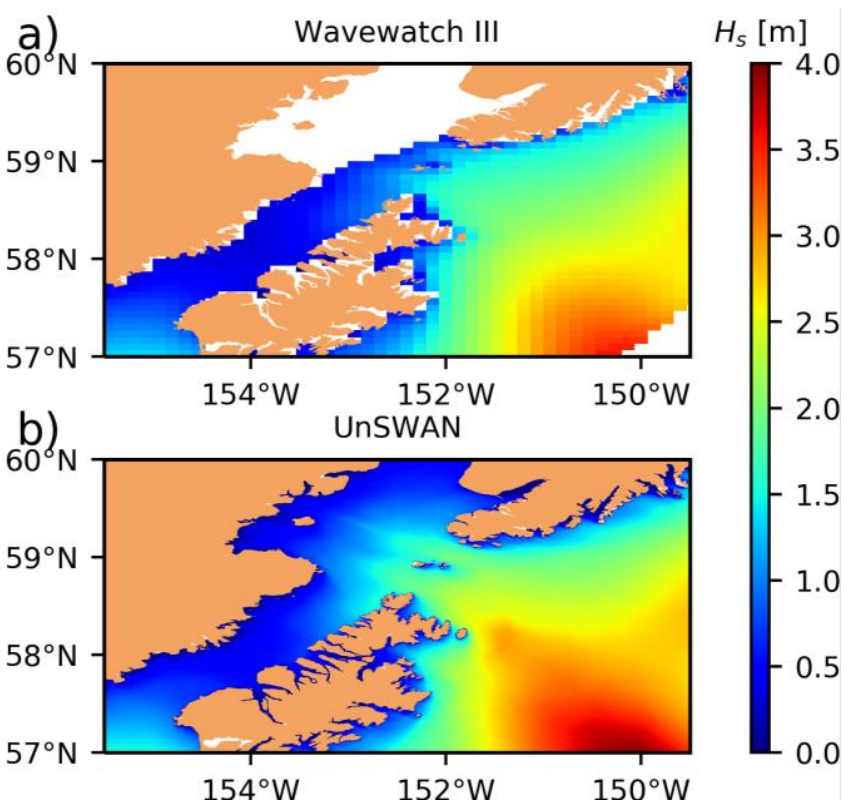

Fig. 6. Significant wave height near Kodiak, Alaska, simulated by Wave Watch III (a) and UnSWAN (b).

Extensive model validation was conducted using observed wave data at dozens of buoy stations for each region, including both spectral and bulk-parameter data. Following the IEC TS standards for model validation [1], the six IEC wave resource parameters derived by model hindcasts compared well with those derived from buoy measurements. These six resource parameters include omnidirectional wave power, significant wave height, energy period, spectral width, direction of maximum directionally resolved wave power, and directionality coefficient. Example time-series comparisons of modelled and observed six IEC parameters at selected NDBC buoys in West Coast, East Coast and Alaska Coast are shown in Fig. 7 to Fig. 9, respectively. Overall, the UnSWAN simulations accurately predicted the different wave climates in different regions, especially the seasonal variations with extreme waves in the winter and calm sea state in the summer. Energy period in both West Coast and Alaska is longer than that in the East Coast, which is below $10 \mathrm{~s}$ most of the year. Another distinct feature is that the direction of maximum directionally resolved wave power is primarily from the west (270 deg) in the West Coast (at buoy 46027) but from all the directions in the East Coast (at buoy 46008) and Alaska (at buoy 46075) where extreme weather events like hurricanes and extra-tropical storms are active. The error statistics of model-data comparisons 


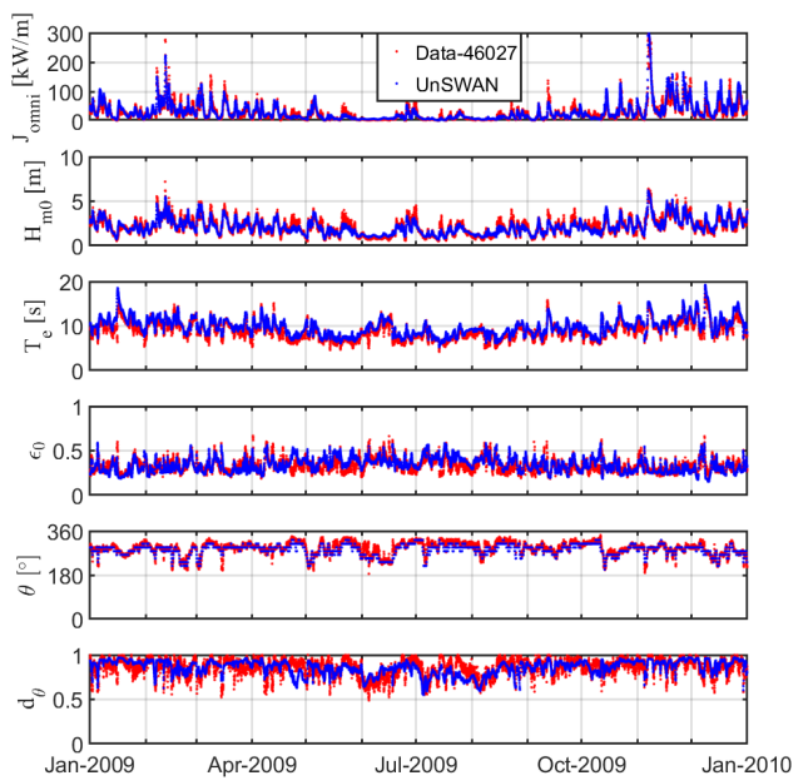

Fig. 7. Comparison of observed and simulated six IEC resource parameters for year 2009 at NDBC buoy 46027 in the West Coast. From top to bottom: omnidirectional wave power, significant wave height, energy period, spectral width, direction of maximum directionally resolved wave power, and directionality coefficient. Buoy location is shown in Fig. 2.

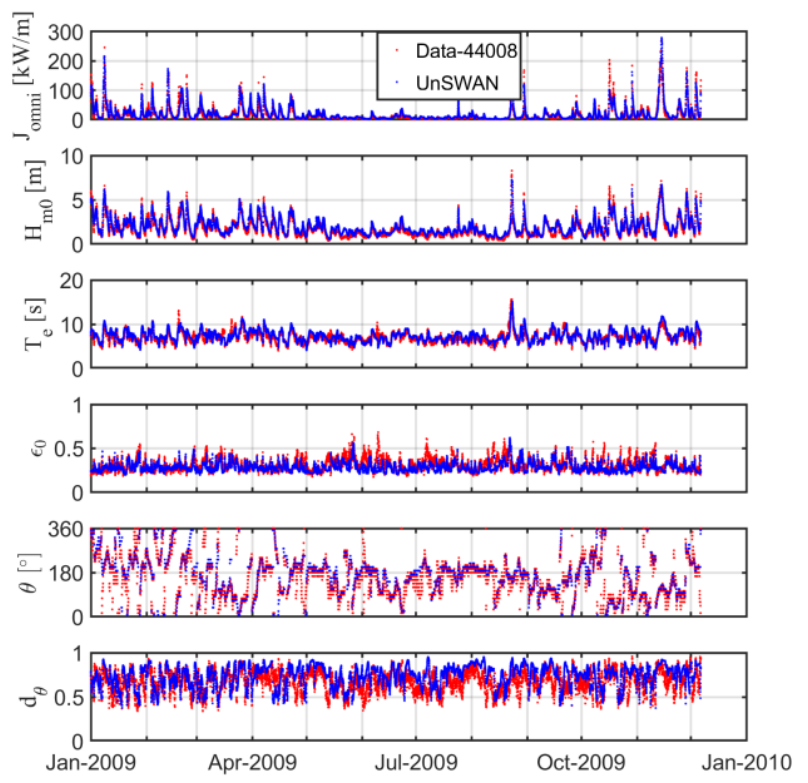

Fig. 8. Comparison of observed and simulated six IEC resource parameters for year 2009 at NDBC buoy 44008 in the East Coast. From top to bottom: omnidirectional wave power, significant wave height, energy period, spectral width, direction of maximum directionally resolved wave power, and directionality coefficient. Buoy location is shown in Fig. 3.

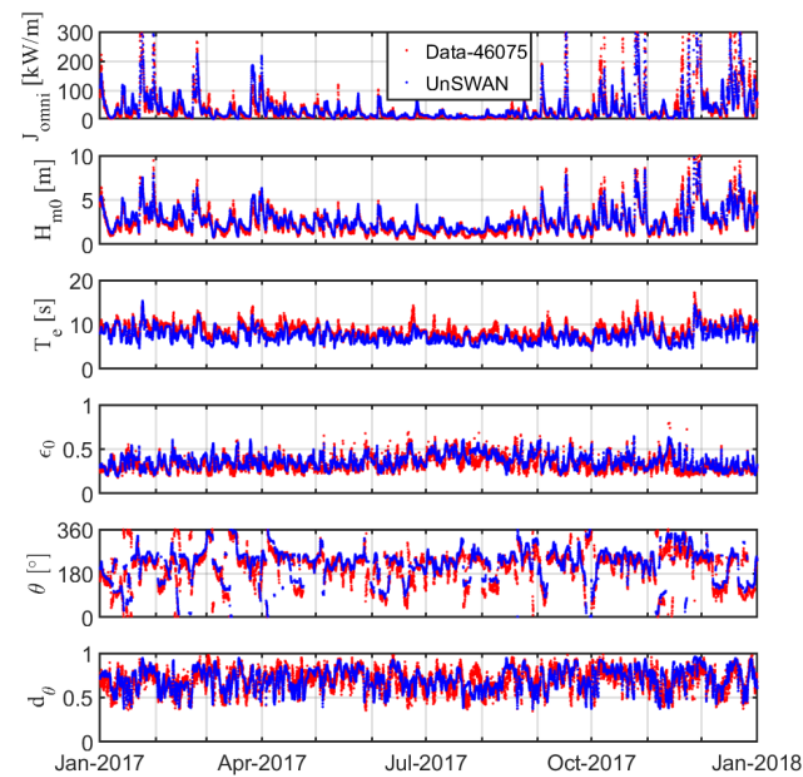

Fig. 9. Comparison of observed and simulated six IEC resource parameters for year 2017 at NDBC buoy 46075 in the Alaska Coast region. From top to bottom: omnidirectional wave power, significant wave height, energy period, spectral width, direction of maximum directionally resolved wave power, and directionality coefficient. Buoy location is shown in Fig. 4.

The improved accuracy of these 32-year regional hindcasts compared to the 30-year NOAA WWIII hindcast has been demonstrated [7-9]; particularly for large wave heights , and rare events, e.g., those occurring at a 50-year recurrence interval [12]. There error statistics for the predicted six IEC parameters at the three example buoy stations are shown in Table 2 to Table 4, respectively.

TABLE 2

MODEL PERFORMANCE METRICS AT BUOY 46027 FOR 2009

\begin{tabular}{ccccccc}
\hline Parameter & RMSE & $\begin{array}{c}\text { PE } \\
(\%)\end{array}$ & SI & Bias & $\begin{array}{c}\text { Bias } \\
(\%)\end{array}$ & R \\
\hline$J(\mathrm{~kW} / \mathrm{m})$ & 14.91 & 26.4 & 0.53 & 2.22 & 7.8 & 0.90 \\
$H_{s}(\mathrm{~m})$ & 0.43 & 3.2 & 0.20 & -0.03 & -1.4 & 0.89 \\
$T_{e}(\mathrm{~s})$ & 1.28 & 10.9 & 0.14 & 0.89 & 9.9 & 0.90 \\
$\epsilon_{0}(-)$ & 0.07 & 4.0 & 0.21 & 0.01 & 2.4 & 0.59 \\
$\theta($ degrees $)$ & 15.64 & -2.1 & 0.05 & -6.8 & -2.4 & 0.84 \\
$d_{\theta}(-)$ & 0.08 & 1.2 & 0.09 & 0.00 & 0.5 & 0.58 \\
\hline
\end{tabular}

TABLE 3

MODEL PERFORMANCE METRICS AT BUOY 44008 FOR 2009

\begin{tabular}{ccccccc}
\hline Parameter & RMSE & $\begin{array}{c}\text { PE } \\
(\%)\end{array}$ & SI & Bias & $\begin{array}{c}\text { Bias } \\
(\%)\end{array}$ & $\mathrm{R}$ \\
\hline$J(\mathrm{~kW} / \mathrm{m})$ & 15.56 & 57.3 & 0.90 & 3.75 & 21.8 & 0.88 \\
$H_{s}(\mathrm{~m})$ & 0.43 & 19.4 & 0.24 & 0.21 & 11.9 & 0.94 \\
$T_{e}(\mathrm{~s})$ & 0.85 & 5.0 & 0.12 & 0.32 & 4.6 & 0.81 \\
$\epsilon_{0}(-)$ & 0.07 & -6.0 & 0.22 & -0.03 & -8.5 & 0.51 \\
$\theta($ degrees $)$ & 42.51 & 17.9 & 0.27 & 10.24 & 6.5 & 0.68 \\
$d_{\theta}(-)$ & 0.14 & 11.2 & 0.20 & 0.06 & 9.1 & 0.50 \\
\hline
\end{tabular}


TABLE 4

MODEL PERFORMANCE METRICS AT BUOY 46075 FOR 2018

\begin{tabular}{ccccccc}
\hline Parameter & RMSE & $\begin{array}{c}\text { PE } \\
(\%)\end{array}$ & SI & Bias & $\begin{array}{c}\text { Bias } \\
(\%)\end{array}$ & $\mathrm{R}$ \\
\hline$J(\mathrm{~kW} / \mathrm{m})$ & 39 & 46 & 0.88 & 1.27 & 2.9 & 0.93 \\
$H_{s}(\mathrm{~m})$ & 0.56 & 15 & 0.22 & 0.18 & 7.14 & 0.95 \\
$T_{e}(\mathrm{~s})$ & 1.35 & -12 & 0.16 & -1.0 & -12. & 0.86 \\
$\epsilon_{0}(-)$ & 0.07 & 11 & 0.21 & 0.03 & 9.1 & 0.71 \\
$\theta($ degrees $)$ & 44.55 & 18 & 0.22 & 15.5 & 7.5 & 0.58 \\
$d_{\theta}(-)$ & 0.11 & 3 & 0.16 & 0.01 & 1.6 & 0.62 \\
\hline
\end{tabular}

\section{2D distribution of IEC parameters}

Although the annual mean of the omnidirectional wave power is one of the common parameters used in a wave resource assessment at a selected project site, the IEC recommends six wave parameters for resource characterization. Both WWIII and UnSWAN model codes were modified to compute these parameters internally from the full simulated spectrum. This allows storing the IEC resource parameters at high spatial density due to the reduced need to store full two-dimensional wave spectra at every grid/mesh point.

Examples of 2D distributions of the six IEC parameters for the entire Alaska EEZ region averaged for year 2009 are shown in Fig. 10. The 2D distribution of the IEC parameters details the wave climate variability at a fine spatial resolution. In general, south of the Aleutian Islands wave power is high because of the presence of large swells with long wave energy periods propagating from the south. Spectral width is small in most of the region except near the Alaska Peninsula and Kodiak areas. Although most of the maximum wave energy is coming from the south and southwest (180 - $270 \mathrm{deg})$, north of the Aleutian Islands the maximum energy is dominated from the north and northwest (300 - $360 \mathrm{deg})$. Directionality coefficient is close to 1 near the Alaska Peninsula and the Gulf of Alaska, and is around 0.7 in the rest of the region.
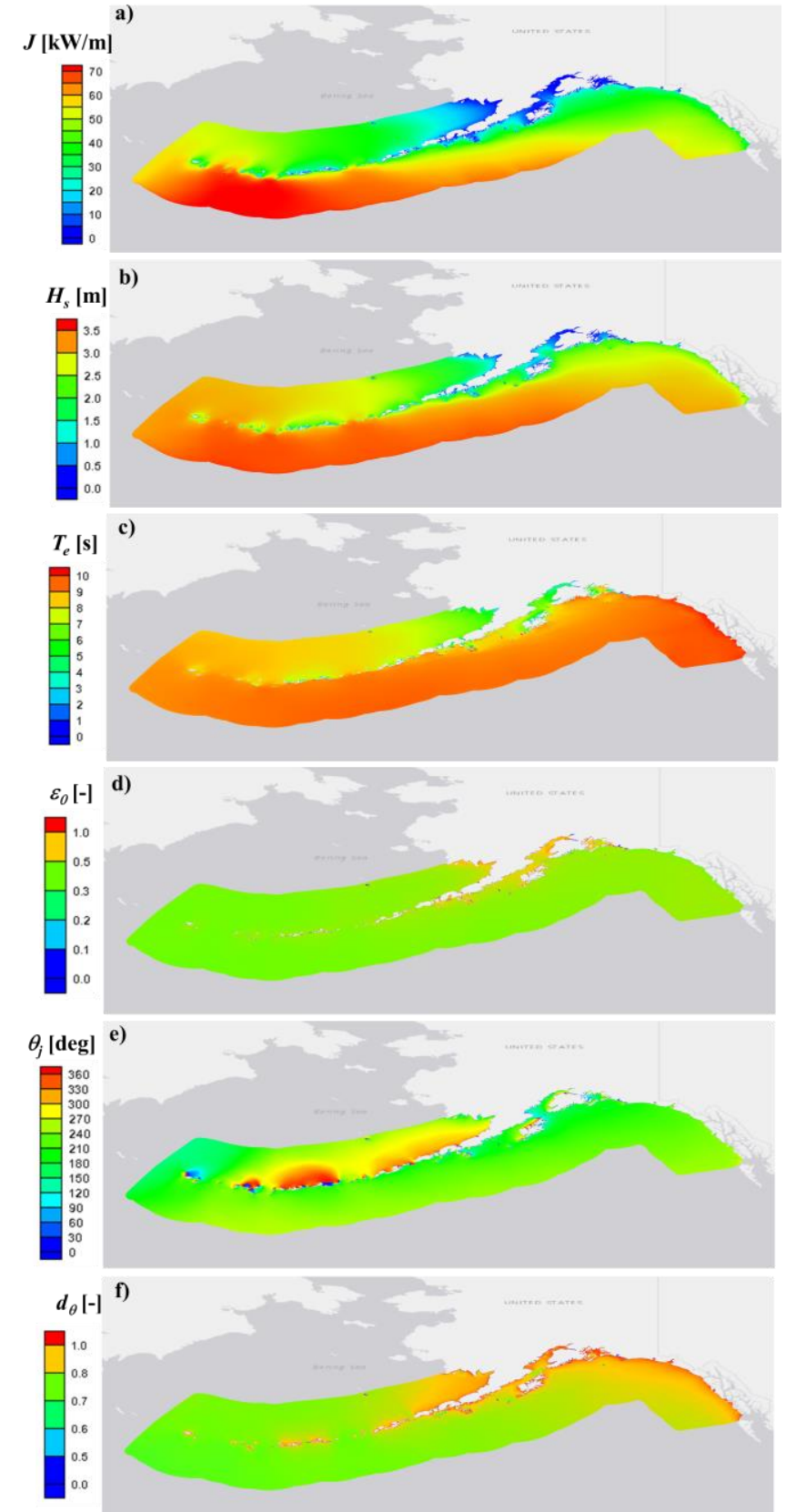

Fig. 10. Simulated annual averages of six IEC wave resource parameters for year 2009 in Alaska region: (a) omnidirectional wave power; (b) significant wave height; (c) energy period; (d) spectral width; (e) direction of maximum directionally resolved wave power, and (f) directionality coefficient.

\section{E. Classification}

Modelled spectral partitioned wave parameters output from the present study's 32-year regional hindcasts will be used to upgrade the beta-version US wave energy resource classification system [13] designed to facilitate energy planning and resource assessment, and the wave conditions classification system [12] designed to streamline WEC design. Parameters in both classification systems are currently calculated using modelled outputs from the phase II WWIII 30-year hindcast [14], which, as mentioned, is a relatively low reconnaissance-level resolution at 4 arc-minutes, and does not resolve nearshore regions. 


\section{CONCLUSION}

The present study demonstrates that the modelling approach with combined WWIII and UnSWAN models provides a powerful and efficient method to accurately simulate wave climates and to calculate IEC parameters to characterize wave energy resources with sufficient spatial and temporal coverage, and at fine resolutions to support feasibility (Class 2) and design (Class 3) assessments. Comparing results to the NOAA 4 ' WWIII® hindcast, the present study's UnSWAN hindcast shows an overall improvement in predicting large wave heights in the West Coast $[7,15]$. In addition, the USWAN model domain covers shallow- near shore regions not modelled in the previous WWIII® hindcast.

This high-resolution regional hindcast effort provides detailed and comprehensive datasets of the U.S. wave energy resources that will dramatically reduce the cost of entry into the wave technology development market. Without this data technology and project developers would need to collect their own information on resource characteristics at sites of interest. The modelling efforts in this project cover all the U.S. EEZ regions, and, therefore, large high-performance-commutating facilities like those found at DOE national laboratories are required to conduct these expensive model simulations.

\section{ACKNOWLEDGEMENT}

This study was funded by the U.S. Department of Energy, Office of Energy Efficiency and Renewable Energy, Water Power Technology Office, under contract DE-AC05-76RL01830 to Pacific Northwest National Laboratory. Sandia National Laboratories is a multimission laboratory managed and operated by National Technology and Engineering Solutions of Sandia, LLC., a wholly owned subsidiary of Honeywell International, Inc., for the U.S. Department of Energy's National Nuclear Security Administration under contract DE-NA0003525. This paper describes objective technical results and analysis. Any subjective views or opinions that might be expressed in the paper do not necessarily represent the views of the U.S. Department of Energy or the United States Government. All model simulations were performed at the PPNL Institutional Computing (PIC) facility and the Sky Bridge high performance computing cluster hosted at Sandia National Laboratories.

\section{REFERENCES}

[1] IEC, Marine energy - wave, tidal and other water current converters - Part 101: Wave energy resource assessment and characterization, 2015, International Electrotechnical Commission: Geneva, Switzerland.

[2] EPRI, Mapping and Assessment of the United States Ocean Wave Energy Resource, in EPRI 2011 Technical Report to U.S. Department of Energy2011, Electric Power Research Institute: Palo Alto, California.
[3] Tolman, H.L., User manual and system documentation of WAVEWATCH III® version 4.18, 2014, National Oceanic and Atmospheric Administration, National Weather Service, National Centers for Environmental Prediction: College Park, MD 20740. p. 311.

[4] SWAN, SWAN: User Manual, Cycle III version 41.01A, 2015, Delft University of Technology: Delft, The Netherlands.

[5] Ardhuin, F., E. Rogers, A.V. Babanin, J.F. Filipot, R. Magne, A. Roland, A. van der Westhuysen, P. Queffeulou, J.M. Lefevre, L. Aouf, and F. Collard, Semiempirical Dissipation Source Functions for Ocean Waves. Part I: Definition, Calibration, and Validation. Journal of Physical Oceanography, 2010. 40(9): p. 1917-1941.

[6] Dietrich, J.C., S. Tanaka, J.J. Westerink, C.N. Dawson, R.A. Luettich, M. Zijlema, L.H. Holthuijsen, J.M. Smith, L.G. Westerink, and H.J. Westerink, Performance of the UnstructuredMesh, SWAN plus ADCIRC Model in Computing Hurricane Waves and Surge. Journal of Scientific Computing, 2012. 52(2): p. 468497.

[7] Yang, Z., W.C. Wu, T. Wang, and L. Castrucci, High-Resolution Regional Wave Hindcast for the U.S. West Coast, 2018, PNNL: Richland, WA. p. 276.

[8] Allahdadi, M.N., B. Gunawan, J. Lai, R.Y. He, and V.S. Neary, Development and validation of a regional-scale high-resolution unstructured model for wave energy resource characterization along the US East Coast. Renewable Energy, 2019. 136: p. 12.

[9] Yang, Z., W.C. Wu, T. Wang, G. Garcia-Medina, and L. Castrucci, High-Resolution Regional Wave Hindcast for the U.S. Alaska Coast, 2019, PNNL: Richland, WA.

[10] Yang, Z.Q., V.S. Neary, T.P. Wang, B.D. Gunawan, A.R. Dallman, and W.C. Wu, A wave model test bed study for wave energy resource characterization. Renewable Energy, 2017. 114: p. 132-144.

[11] Wang, T.P., Z.Q. Yang, W.C. Wu, and M. Grear, A Sensitivity Analysis of the Wind Forcing Effect on the Accuracy of Large-Wave Hindcasting. Journal of Marine Science and Engineering, 2018. 6(4).

[12] Neary, V.S., B.E. Seng, Z. Yang, N. Allahdadi, R.Y. He, and T. Wang, Model performance predicting extreme wave heights for project risk assessment and WEC design, in European Wave and Tidal Energy Conference2019: Napoli, Italy. p. 8.

[13] Ahn, S., K.A. Haas, and V.S. Neary, Wave energy resource classification system for US coastal waters. Renewable \& Sustainable Energy Reviews, 2019. 104: p. 15.

[14] Chawla, A., D.M. Spindler, and H.L. Tolman, Validation of a thirty year wave hindcast using the Climate Forecast System Reanalysis winds. Ocean Modelling, 2013. 70: p. 189-206. 